\title{
O ESPAÇO RURAL BRASILEIRO EM TRANSFORMAÇÃO*
}

\author{
Ivo ELESBÃO ${ }^{1}$
}

\begin{abstract}
Resumo - O espaço rural passou e está passando por muitas mudanças, tornando-se com isso cada vez mais complexo o desafio de entender seu funcionamento. Neste artigo, analisam-se as transformações em curso no espaço rural brasileiro, apoiados numa revisão bibliográfica de autores que têm o rural como objeto de estudo. Constatou-se que ocorreu uma evolução dos usos do espaço rural, com o surgimento e emergência de novas aptidões, que levam a um novo olhar sobre o rural e a uma redefinição das suas atribuições. Nesse sentido, é fundamental que as estratégias de desenvolvimento levem em consideração a grande diversidade e valorizem as potencialidades que cada local oferece, para que se consiga ultrapassar a situação de abandono em que muitas áreas rurais brasileiras se encontram.
\end{abstract}

Palavras-chave: Espaço rural, mudanças, Brasil.

\begin{abstract}
TRANSFormation In the BRAZILIAN RURAL SPACE. The Brazilian rural space has undergone, and continues to undergo, many significant changes. As a consequence of this, its functioning is becoming increasingly complex, and understanding it presents a great challenge. The aim of this article is to analyze the transformations currently under way in the Brazilian rural space, based on a literature survey of previous research on rural issues. This survey makes it possible to identify a distinctive shift in the use of rural space, characterized by the appearance and emergence of new attitudes, which has led to a new way of regarding the "rural" and to a redefinition of its attributes. It is therefore essential for development strategies to take into account the very significant diversity that characterizes the Brazilian rural space and to acknowledge the potential of each place, so that the current situation of abandonment facing many Brazilian rural areas may be overcome.
\end{abstract}

Key words: Rural space, changes, Brazil.

* Recebido: 12/06/2007. Revisto: 20/09/2007. Aceite: 30/11/2007.

1 Doutorando em Geografia - UNESP/Campus de Rio Claro, SP, Brasil. Professor da Universidade de Cruz Alta - UNICRUZ, Cruz Alta, RS, Brasil. E-mail: ivoelesbao@yahoo.com.br 
Résumé - L'ESPACE RURAL BRESILIEN EN TRANSFORMATION. L'espace rural a subi beaucoup de changements au Brésil. Le défi de comprendre son fonctionnement devient donc de plus en plus complexe. On analyse les transformations en cours, en s'appuyant sur la révision bibliographique des auteurs qui ont étudié le phénomène rural. L'évolution de la mise en valeur de l'espace rural résulte de l'émergence et du développement de nouvelles aptitudes. Il en résulte un nouveau regard sur celui-ci et une redéfinition de ses attributions. Les stratégies de développement doivent prendre en compte la grande diversité et les potentialités des diverses régions, pour que puisse être dépassée la situation d'abandon qui afflige plusieurs aires rurales.

Mots-clés: Espace rural, changements, Brésil.

\section{INTRODUÇÃO}

A compreensão das transformações que aconteceram e estão acontecendo no rural brasileiro passa, necessariamente, pelo estudo do processo histórico de constituição do rural enquanto espaço de produção e reprodução social de sua população. O rural, além de espaço produtivo, é lugar de vida, de interação social, condição muitas vezes colocada em segundo plano quando da sua análise. A esfera produtiva sempre esteve em destaque, seja quando da produção de produtos para exportação, o que aconteceu durante a maior parte da história econômica brasileira, seja no fornecimento de matérias-primas para o surgimento e consolidação da agroindústria nacional, como também atualmente, sendo a principal responsável pelos saldos positivos na balança comercial.

As mudanças observadas no espaço rural dos países desenvolvidos passam também a ser detectadas no rural brasileiro, que hoje é estudado à luz dessas transformações, ampliando o enfoque, que outrora recaía somente na produção de alimentos e matérias-primas, para considerar também a relação com as atividades não agrícolas. Estas atividades, praticadas por componentes de muitas famílias rurais, ganham importância na busca da compreensão das transformações de que o rural brasileiro vem sendo palco e que se intensificaram nos últimos tempos.

Neste artigo, analisam-se as transformações em curso, apoiando-nos para isso, em uma revisão bibliográfica que tem o rural como objeto de estudo e que busca compreender as mudanças que estão ocorrendo nesse espaço. Necessário se faz ressaltar que esta nem de longe pode ser considerada uma reflexão exaustiva, pois entendemos as limitações ao analisar um espaço que é estudado por várias áreas da Ciência e que congrega uma enorme quantidade de trabalhos produzidos sobre o tema.

Nossa análise será dividida em duas partes e irá se pautar em algumas mudanças históricas e na complexidade de relações de que o rural atualmente se reveste. Na primeira parte buscaremos discorrer sobre as transformações no rural brasileiro ao longo do século XX enfocando quatro grandes acontecimentos: o fim do último grande ciclo econômico (ciclo do café); o processo de modernização da agricultura; a migração campo/cidade; e o reconhecimento da 
importância da agricultura familiar. Na segunda parte nossa análise terá como base a emergência de novas atividades e novos valores no rural contemporâneo, os quais representam a diversidade de situações na teia de relações que se estabelecem entre o rural e o urbano.

\section{O ESPAÇO RURAL BRASILEIRO AO LONGO DO SÉCULO XX}

O território rural brasileiro sempre foi olhado como espaço de produção de alimentos, matérias-primas e fornecedor de mão-de-obra para o processo de industrialização, sendo estas as funções clássicas desempenhadas pela agricultura no processo de desenvolvimento. De acordo com Albuquerque e Nicol (1987) a agricultura desempenharia cinco papéis básicos com vista a dar suporte ao processo de desenvolvimento de outros setores da economia: a) liberação da mão-de-obra para o setor industrial; b) fornecimento de produtos alimentícios e matérias-primas; c) suprimento de capital para o financiamento de investimentos industriais; d) suprimento de divisas estrangeiras através da exportação de produtos agrícolas; e) criação de um mercado interno para produtos industriais.

$\mathrm{Na}$ análise da formação econômica do Brasil, percebe-se que ela se desenvolveu em ciclos, sendo os principais o do açúcar, o da mineração e o do café. Não se pode esquecer também a pecuária, a borracha e outros também relevantes, porém de menor importância. O café foi o último grande ciclo e o seu declínio marca uma maior diversificação não só da base da economia mas principalmente da produção agropecuária.

\section{O fim do último grande ciclo econômico}

O café encontrou no Brasil um ambiente muito favorável para o seu desenvolvimento. Entre os vários fatores que contribuiram para isso pode-se destacar: o aumento na demanda mundial do produto; a crise na economia mineira, que possibilitou a liberação de mão-de-obra para outras atividades; a fertilidade natural da terra nos arredores do Rio de Janeiro; e a transferência da Corte para este local.

Durante a expansão cafeeira as ações governamentais foram direcionadas especificamente para este setor, devido não só à importância do café para a economia brasileira, mas principalmente, à influência política das elites agrárias. De acordo com Silva (1988: 252) "a economia brasileira era o café e todas as políticas do Estado brasileiro giravam em torno da política de valorização do café: compra de excedentes, financiamentos externos, impostos sobre exportação, etc.".

O café ainda teve grande importância para a economia brasileira nas primeiras três décadas do século XX, chegando inclusive, entre os anos 1924-1929, a responder por $72,5 \%$ do valor total das exportações do país. Diante deste quadro fica mais perceptível a grande influência dos cafeicultores nas decisões 
políticas do país e nas medidas adotadas, voltadas para a proteção de seus interesses. Para Furtado (1964: 215), "a economia havia desenvolvido uma série de mecanismos pelos quais a classe dirigente cafeeira lograra transferir para o conjunto da coletividade o peso da carga nas quedas cíclicas anteriores”.

Em Fevereiro de 1906 foi firmado o chamado Convênio de Taubaté (na cidade paulista de mesmo nome), conhecido como política de "valorização do café". Segundo Furtado (1964: 207), os principais pontos dessa política eram os seguintes: "a) com o fim de restabelecer o equilíbrio entre oferta e procura de café, o governo interviria no mercado para comprar os excedentes; b) o financiamento dessas compras se faria com empréstimos estrangeiros; c) o serviço desses empréstimos seria coberto com um novo imposto cobrado em ouro sobre cada saca de café exportada; d) a fim de solucionar o problema a mais longo prazo, os governos dos estados produtores deveriam desencorajar a expansão das plantações".

A política de valorização acordada pelo Convênio de Taubaté fez com que os preços se mantivessem num patamar interessante para os produtores. Com isso, os lucros continuavam elevados, o que fazia com que novos investimentos continuassem a ser feitos na produção, ocasionando uma pressão cada vez maior sobre a oferta de café. Esse mecanismo de defesa da economia cafeeira transferia o problema para o futuro, pois a política de desestímulo era impraticável sem a criação de alternativas. O desequilíbrio máximo aconteceu então em 1929, quando o valor dos estoques ultrapassou 10\% do Produto Interno Bruto (Furtado, 1964).

No entanto, a crise mundial de 1929 encontrou a economia brasileira bastante fragilizada devido à grande dependência e vulnerabilidade externa. Com isso, ocorre o rompimento do modelo primário-exportador, que era a base da economia até então e que tinha a agropecuária como setor dinâmico que, "além de produzir os alimentos requeridos pela população urbana, obtinha através de suas exportações, as divisas necessárias às importações de bens de consumo para a população" (Fürstenau, 1987: 139).

Devido à crise, ocorreu uma grande diminuição na receita das exportações e consequentemente redução da capacidade de importar, fazendo com que o governo adotasse medidas para defender o mercado interno, o que favoreceu a industrialização. Para Furtado (1964: 267) "a primeira metade do século XX está marcada pela progressiva emergência de um sistema cujo principal centro dinâmico é o mercado interno".

O período seguinte à crise e que se estendeu até a década de 60 , é conhecido como industrialização substitutiva de importações e divide-se em duas fases: uma de 1930 até o final dos anos 40, chamada de transição para uma economia urbana e industrial; outra a partir de meados da década de 50, quando ocorreu aceleração do desenvolvimento industrial com uma crescente subordinação do setor agropecuário ao setor industrial (Fürstenau, 1987).

Em meados do século XX, a diferença nos níveis regionais de renda havia aumentado significativamente, embora, nesta época, a economia brasileira tenha 
alcançado certo nível de articulação entre as diferentes regiões. De acordo com Furtado (1964: 272), "à medida que o desenvolvimento industrial se sucedia à prosperidade cafeeira, acentuava-se a tendência à concentração regional de renda".

É nas décadas de 50,60 e 70 que se desenvolve o processo que ficou conhecido mundialmente como "Revolução Verde" e que buscava elevar a produtividade através do uso intensivo de novos fatores de produção, como sementes melhoradas, fertilizantes, agrotóxicos e mecanização. No Brasil, uma das principais políticas com o objetivo de modernizar a agropecuária foi a concessão de crédito rural.

\section{O processo de modernização da agropecuária}

Os meados da década de 1960 marcam o desencadeamento em larga escala no país, de um conjunto de transformações socioeconômicas que configuram um novo padrão de desenvolvimento rural, o qual se convencionou chamar de "modernização conservadora", caracterizada, segundo Delgado (1983), por: 1) rápido crescimento das exportações e da urbanização; 2) constituição e diversificação dos vários ramos do Complexo Agroindustrial (CAI); 3) organização de um novo financiamento das atividades agropecuárias através do Sistema Nacional de Crédito Rural; 4) um novo padrão de regulação do setor rural pelo Estado.

O crédito rural subsidiado foi o principal instrumento da política de "modernização conservadora" que permitiu unir os interesses das classses dominantes em torno da estratégia de modernização e possibilitou ao Estado restabelecer o seu poder regulador macroeconômico através de uma política monetária expansionista (Silva, 1998).

De acordo com Moreira (1999: 52) "desta forma, o grande proprietário aprofunda e intensifica sua condição de grande produtor, de acordo com as novas 'regras do mercado' e amparado pelo apoio público ou privado à modernização". Assim, como não ocorrem alterações nas relações de poder e na estrutura da propriedade da terra, pode falar-se de uma "modernização conservadora".

Conforme Delgado (1983), é no final dos anos 60 que se constitui o Complexo Agro-Industrial (CAI), o qual é caracterizado pela implantação de um setor industrial produtor de bens de produção para a agricultura e pelo desenvolvimento de um mercado para produtos industrializados de origem agropecuária.

A relação imbricada entre agropecuária e indústria, que passa a haver a partir do processo de modernização, altera profundamente as relações socioeconômicas no campo. Para Moreira (1999: 38), "o pacto político fundamental que viabiliza esse padrão de modernização tecnológica se sedimenta entre 1964 e 1968 e consiste na manutenção do elevado padrão de concentração da propriedade e uso da terra".

No quadro I pode-se verificar a estrutura fundiária brasileira por grupos de área, no período de 1940 a 1996. Em relação ao número de estabelecimentos, observa-se que houve um aumento progressivo e significativo entre 1940 e 1980, 
passando de pouco mais de 1,9 milhões para mais que 5,1 milhões, ou seja, o total de estabelecimentos aumentou $170,9 \%$ no período. No entanto houve uma redução de 5,8\% entre 1980 e o biênio 1995/96.

Quadro I - Número de estabelecimentos por grupos de área. Brasil, 1940-96

Table I - Number of establishments per groups of area. Brazil, 1940-1996

\begin{tabular}{lccccccc}
\hline & $\mathbf{1 0}$ & $\mathbf{1 0} \leq \mathbf{5 0}$ & $\mathbf{> 5 0} \leq \mathbf{1 0 0}$ & $\mathbf{> 1 0 0} \leq \mathbf{1 0 0 0}$ & $\mathbf{> 1 0 0 0}$ & $\begin{array}{c}\text { Sem } \\
\text { declaração }\end{array}$ & Total \\
\cline { 2 - 8 } Anos & $\begin{array}{c}\text { Número } \\
\text { em } \\
\text { milhares }\end{array}$ & $\begin{array}{c}\text { Número } \\
\text { em } \\
\text { milhares }\end{array}$ & $\begin{array}{c}\text { Número } \\
\text { em } \\
\text { milhares }\end{array}$ & $\begin{array}{c}\text { Número } \\
\text { em } \\
\text { milhares }\end{array}$ & $\begin{array}{c}\text { Número } \\
\text { em } \\
\text { milhares }\end{array}$ & $\begin{array}{c}\text { Número } \\
\text { em } \\
\text { milhares }\end{array}$ & $\begin{array}{c}\text { Número } \\
\text { em } \\
\text { milhares }\end{array}$ \\
\hline 1940 & 654,56 & 770,73 & 204,71 & 243,82 & 27,81 & 2,96 & 1904,59 \\
1950 & 710,93 & 833,23 & 219,33 & 268,16 & 32,63 & 0,36 & 2064,64 \\
1960 & 1495,02 & 1218,75 & 272,66 & 314,83 & 32,48 & 4,02 & 3337,80 \\
1970 & 2519,63 & 1592,54 & 341,85 & 414,75 & 36,88 & 18,38 & 4924,02 \\
1980 & 2598,02 & 1625,38 & 391,39 & 488,52 & 47,85 & 8,70 & 5159,85 \\
$1995-96$ & 2402,37 & 1516,11 & 400,38 & 469,96 & 49,35 & 21,68 & 4859,87 \\
\hline
\end{tabular}

Fonte: IBGE (2006).

Ao analisarem-se os grupos de áreas, pode-se perceber um aumento na participação de estabelecimentos com menos que 10 ha, passando de pouco mais que $34 \%$ em 1940 e 1950 para cerca de $50 \%$ a partir de 1970 . No entanto, observa-se uma relação inversa para os estabelecimentos de 10 a menos que 50 ha, que foram reduzindo sua participação no total de $40,5 \%$ em 1940 para 31,2\% em 1995-96. Já os estabelecimentos de 50 a menos que 100 ha tiveram uma participação média de $8,7 \%$ no período analisado, enquanto que para os de 100 a menos que 1000 ha a média foi de $10,5 \%$. Ao agruparem-se os estabelecimentos com menos que 50 ha, percebe-se que estes representavam em 1995-96, $80,6 \%$ do total.

Quanto à área dos estabelecimentos, verifica-se (quadro II), que houve um aumento de 78,8\% no total da área, passando de 197 milhões em 1940 para 353 milhões em 1995-96. Observa-se que todos os grupos considerados no período tiveram aumento na área, com destaque para os estabelecimentos com menos de 10 ha, que tiveram o total da área aumentado 172,4\% entre 1940 e 1995-96. Os estabelecimentos que tiveram o menor ganho percentual no período foram os que tinham mais de 1000 ha, que aumentaram sua área total em 67,0\%. Em relação ao total, verifica-se que a área dos estabelecimentos com menos de 10 ha representava em média $2,2 \%$ no período, enquanto a área dos estabelecimentos com mais de 1000 ha equivalia a $45,5 \%$.

Todos os grupos de áreas tiveram redução no tamanho médio dos estabelecimentos entre 1940 e 1995-96. A redução percentual mais significativa verificou-se nos estabelecimentos com menos de 10 ha, passando de 4,4 ha para 
3,3 ha, ou seja, os chamados minifúndios ficaram ainda menores. Os estabelecimentos com mais de 1000 ha possuíam em 1940 uma área média de 3435,1 ha, que foi reduzida em 5,9\% em relação a 1995-96, passando para 3231,9 ha. Comportamento parecido tiveram os outros grupos de área, diminuindo menos que $6,0 \%$ em seu tamanho médio.

Quadro II - Área dos estabelecimentos por grupo de área. Brasil, 1940-96 Table II - Area of the establishments per groups of area. Brazil, 1940-1996

\begin{tabular}{lcccccc}
\hline \multirow{2}{*}{ Anos } & $\mathbf{s 1 0}$ & $\mathbf{> 1 0} \mathbf{5 0}$ & $\mathbf{> 5 0} \leq \mathbf{1 0 0}$ & $\mathbf{> 1 0 0} \leq \mathbf{1 0 0 0}$ & $\mathbf{> 1 0 0 0}$ & Total \\
\cline { 2 - 8 } & $\begin{array}{c}\text { Área } \\
\text { em milhares } \\
\text { de ha }\end{array}$ & $\begin{array}{c}\text { Área } \\
\text { em milhares } \\
\text { de ha }\end{array}$ & $\begin{array}{c}\text { Área } \\
\text { em milhares } \\
\text { de ha }\end{array}$ & $\begin{array}{c}\text { Área } \\
\text { em milhares } \\
\text { de ha }\end{array}$ & $\begin{array}{c}\text { Área } \\
\text { emilhares } \\
\text { de ha }\end{array}$ & $\begin{array}{c}\text { Área } \\
\text { em milhares } \\
\text { de ha }\end{array}$ \\
\hline 1940 & 2893,44 & 18956,07 & 14256,09 & 66185,00 & 95529,65 & 197720,25 \\
1950 & 3025,37 & 20185,87 & 15376,88 & 75520,72 & 118102,27 & 232211,11 \\
1960 & 5952,38 & 28503,32 & 19062,97 & 86029,46 & 110314,01 & 249862,14 \\
1970 & 9083,50 & 36167,68 & 23902,02 & 108742,68 & 116249,59 & 294145,47 \\
1980 & 9004,26 & 37136,29 & 27358,05 & 126799,19 & 164556,63 & 364854,42 \\
$1995-96$ & 7882,19 & 35237,83 & 27455,75 & 123541,52 & 159493,95 & 353611,25 \\
\hline
\end{tabular}

Fonte: IBGE (2006).

Em 1940 os estabelecimentos com menos de 10 ha, que representavam $34,4 \%$ do total e eram responsáveis por 1,5\% da área, passaram em 1995-96 a representar $49,4 \%$ dos estabelecimentos e a ocupar 2,2\% da área. Os que tinham mais de 1000 ha, que em 1940 eram $1,5 \%$ do total e tinham 48,3\% da área, passaram em 1995-96 a 1,0\% do total dos estabelecimentos ocupando $45,1 \%$ da área.

Durante o periodo 1995-96 apenas as propriedades com mais de 10000 ha, a concentração da terra fica ainda mais evidente. Havia 1273 propriedades, que correspondiam a apenas $0,04 \%$ do total dos estabelecimentos, que detinham $14,5 \%$ do total de terras. No período analisado o país passou por grandes transformações estruturais mas, como se pode perceber, elas não se estenderam à estrutura fundiária, que praticamente não se modificou, ou seja, a terra continuou concentrada nas mãos dos grandes proprietários.

Essa concentração e a centralização de capital, que são acompanhadas por igual concentração da terra implicam, segundo Moreira (1999: 122), efeitos sobre a pequena propriedade e a produção familiar como: "(1) a perda da propriedade familiar pela impossibilidade de reproduzir-se enquanto proprietários; (2) a tecnificação da pequena produção subordinada à agroindústria, com liberação de força de trabalho familiar que emigra; e (3) a queda do excedente de valor retido pelo produtor familiar - após a reposição dos custos de materiais, força de trabalho de terceiros e juros - inviabiliza a reprodução familiar, forçando a redução do tamanho da família pela migração seletiva de seus membros”. 
O processo de modernização da agricultura brasileira dividiu os agricultores em dois grupos bastante distintos: aqueles que conseguiram acompanhar esse processo e os que não conseguiram. De acordo com Moreira (1999: 130) "o processo de modernização da agricultura não se verifica, no entanto, de forma homogênea: a modernização é lenta em algumas partes, rápida em outras e, fundamentalmente, desigual".

\section{A migração campo/cidade}

As repercussões entre um grupo e outro são bastante diferentes. Os agricultores que se modernizaram e passaram a utilizar os insumos modernos de produção, conseguiram se inserir no mercado, ao passo que os que não conseguiram essa condição - o que constitui a grande maioria - ficaram à margem do sistema, passando a fazer parte de uma massa de excluídos.

Muitos desses compuseram as levas de migrantes campo/cidade, enquanto outros resistiram e ainda resistem a migrar. De acordo com Singer (1998: 29) "como qualquer outro fenômeno social de grande significado na vida das nações, as migrações internas são sempre historicamente condicionadas, sendo o resultado de um processo global de mudança, do qual elas não devem ser separadas". Ainda conforme o autor "a criação de desigualdades regionais pode ser encarada como o motor principal das migrações internas que acompanham a industrialização nos moldes capitalistas".

Essas desigualdades vão influenciar diretamente nos fatores de expulsão. Para o autor eles são de duas ordens: fatores de mudança e fatores de estagnação. Os primeiros são decorrentes da introdução de relações de produção capitalistas no campo, onde o aumento da produtividade do trabalho reduz o nível de emprego. Os fatores de estagnação manifestam-se pela crescente pressão populacional sobre uma limitada área de terra cultivada, entre outros, pela monopolização desta.

Ao analisar-se a relação entre a população rural e urbana ao longo do século XX, verifica-se que até 1960 a maioria da população era rural, mas essa relação se inverteu durante a década de 60 , pois em 1970 a população urbana já representava $55,9 \%$.

Observa-se, no quadro III, que a população rural cresceu até 1970 , começando a reduzir seu número a partir daí, enquanto a população urbana cresceu em todos os períodos analisados. Entre 1950 e 1960 a população urbana aumentou $66,7 \%$ e a rural $16,9 \%$. Já de 1960 para 1970 a urbana cresceu $66,4 \%$ e a rural apenas 5,9\%. No entanto a diferença mais significativa vai dar-se entre os anos de 1970 e 1980 , quando a população urbana aumentou $54,4 \%$ e a rural diminuiu $6,1 \%$.

Estes dados deixam evidente a significativa migração campo/cidade, que ocorreu sobretudo nas décadas de 60 e 70, período marcado por um êxodo rural intenso em direção principalmente às grandes cidades o que trouxe uma série de problemas na sua expansão. 
Quadro III - População urbana, rural e total. Brasil, 1900-2000

Table III - Urban population, rural population and total population. Brazil, 1900-2000

\begin{tabular}{lccc}
\hline Anos & População Urbana & População Rural & Total \\
\hline 1900 & - & - & 17318556 \\
1920 & - & - & 30635605 \\
1940 & 12880182 & 28356133 & 41236315 \\
1950 & 18782891 & 33161506 & 51944397 \\
1960 & 31303034 & 38767423 & 70070457 \\
1970 & 52084984 & 41054053 & 93139037 \\
1980 & 80436409 & 38566297 & 119002706 \\
1991 & 110990990 & 35834485 & 146825475 \\
1996 & 123076831 & 33993332 & 157070163 \\
2000 & 137953959 & 31845211 & 169799170 \\
\hline
\end{tabular}

Fonte: Censos Demográficos IBGE.

As políticas agrícolas que priorizavam a produção de produtos para exportação tiveram importante contribuição nesse processo. Isso fez com que não se alterasse a distribuição de renda no campo, aumentando as desigualdades. Entre as conseqüências estão o aumento da pobreza e os impactos sobre o ambiente.

A década de 70 foi marcada pela abundância de crédito subsidiado. Isto ocorreu devido à necessidade de um mecanismo que financiasse, a taxas subsidiadas e a prazos relativamente longos, uma modernização quase compulsória da base técnica da agropecuária brasileira. A política de crédito rural subsidiado permitiu reunificar os interesses das classes dominantes em torno da estratégia de modernização conservadora (Silva, 1988).

Todo esse processo foi marcado por uma brutal concentração dos recursos com igual concentração da renda. A influência que a classe patronal sempre teve na definição das políticas para o meio rural fez com que se ampliassem as diferenças, ou seja, manteve-se a concentração da terra e a prioridade do incentivo da produção com inserção no mercado internacional.

Embora essa influência não possa ser considerada um resquício histórico (pelo contrário, ainda está bastante presente no círculo do poder), já se pode visualizar uma possibilidade, não de mudança de enfoque, mas pelo menos do reconhecimento da importância da agricultura familiar no desenvolvimento do rural brasileiro. Forma de produção esta, que segundo Veiga (1991: 197), "teve seu desenvolvimento apoiado em todos os países capitalistas centrais".

\section{A importância da agricultura familiar}

Tendo como base os dados do Censo do IBGE de 1995/96, foi elaborado, em cooperação entre o INCRA/FAO (2000), um estudo sobre a situação da 
agricultura familiar no Brasil. Neste estudo o universo familiar foi caracterizado por estabelecimentos que atendiam simultaneamente às seguintes condições: direção dos trabalhos do estabelecimento exercida pelo produtor; trabalho familiar superior ao trabalho contratado; e área máxima regional como limite superior para a área total dos estabelecimentos familiares.

Os estabelecimentos categorizados como sendo de caráter familiar abrangiam $85,2 \%$ em 1995/96, ocupando $30,5 \%$ da área total, produzindo $37,9 \%$ do valor bruto da produção e recebendo $25,3 \%$ do total de financiamento destinado ao setor. Já a agricultura patronal, que representava apenas $11,4 \%$ dos estabelecimentos, congregava $67,9 \%$ da terra, sendo responsável por $61,0 \%$ do valor bruto da produção e por $73,8 \%$ do financiamento (quadro IV).

Quadro IV - Total de estabelecimentos, área, valor bruto da produção (VBP) e financiamento total (FT). Brasil, 1995/96

Table IV - Total number of establishments, area, gross value of production (GVP) and total financing (TF). Brazil, 1995/1996

\begin{tabular}{lrrrrrrrr}
\hline CATEGORIAS & $\begin{array}{c}\text { Total de } \\
\text { estabeleci- } \\
\text { mentos }\end{array}$ & $\begin{array}{c}\text { \% do } \\
\text { total de } \\
\text { estab. }\end{array}$ & $\begin{array}{c}\text { Área } \\
\text { (mil ha) }\end{array}$ & $\begin{array}{c}\text { \% do } \\
\text { total } \\
\text { da área }\end{array}$ & $\begin{array}{c}\text { VBP } \\
\text { (mil R\$) }\end{array}$ & $\begin{array}{c}\text { \% do } \\
\text { total } \\
\text { do VBP }\end{array}$ & $\begin{array}{c}\text { FT } \\
\text { (mil R\$) }\end{array}$ & $\begin{array}{c}\text { \% do } \\
\text { total } \\
\text { do FT }\end{array}$ \\
\hline Familiar & 4139369 & 85,2 & 107768 & 30,5 & 18117725 & 37,9 & 937828 & 25,3 \\
Patronal & 554501 & 11,4 & 240042 & 67,9 & 29139850 & 61,0 & 2735276 & 73,8 \\
Inst. Pia/Relig. & 7143 & 0,2 & 263 & 0,1 & 72327 & 0,1 & 2716 & 0,1 \\
Entid. públicas & 158719 & 3,2 & 5530 & 1,5 & 465608 & 1,0 & 31280 & 0,8 \\
Não identific. & 132 & 0,0 & 8 & 0,0 & 959 & 0,0 & 12 & 0,0 \\
\hline TOTAL & 4859864 & 100,0 & 353611 & 100,0 & 47796469 & 100,0 & 3707112 & 100,0 \\
\hline
\end{tabular}

Fonte: INCRA/FAO (2000: 16).

Quando a análise se faz por regiões, a região Sul é a que apresenta maior proporção de agricultores familiares (90,5\%), abrangendo 43,8\% da área, sendo muito representativa sua participação no percentual do Valor Bruto da Produção $(57,1 \%)$. Ao relacionar as cinco regiões com o total de estabelecimentos familiares do Brasil, constata-se que a região Sul é responsável por 47,3\% do Valor Bruto da Produção da agricultura familiar brasileira, apesar de ter $21,9 \%$ dos estabelecimentos ocupando $18,0 \%$ da área total.

O estudo também faz uma caracterização dos agricultores familiares, classificando-os em quatro tipos, A, B, C e D, associando-os, respectivamente, a agricultores capitalizados, em processo de capitalização, em descapitalização e descapitalizados (quadro V).

Os agricultores familiares do tipo A, ou seja, os capitalizados, compunham o menor grupo $(8,4 \%)$ quanto ao número de estabelecimentos sendo, no entanto, responsáveis por $50,5 \%$ do total do valor bruto da produção da agricultura familiar e recebendo $46,2 \%$ do total do financiamento para a categoria. Já os desca- 
pitalizados (tipo D), eram $46,3 \%$ do total de estabelecimentos, contribuindo com apenas $10,7 \%$ do valor bruto da produção e recebendo $22,0 \%$ do financiamento total para a agricultura familiar.

Verifica-se com isso que, mesmo dentre os agricultores caracterizados como familiares, há uma grande diversidade, principalmente em relação ao valor do que é produzido em cada estabelecimento. Nesse sentido, as políticas para agropecuária necessariamente deveriam considerar essas diferentes condições dos agricultores, pois certamente as prioridades não são as mesmas para todos e vão desde a consolidação dos capitalizados até à busca de reinserção dos descapitalizados e em processo de descapitalização.

Quadro V - Estabelecimentos, área, valor bruto da produção (VBP)

e financiamento total (FT) dos tipos de agricultores familiares. Brasil, 1995-96

Table V-Establishments, area, gross value of production (GVP)

and total financing (TF) of types of family farmers. Brazil, 1995-96

\begin{tabular}{lcccccccr}
\hline TIPOS & $\begin{array}{c}\text { Total de } \\
\text { estabeleci- } \\
\text { mentos }\end{array}$ & $\begin{array}{c}\text { \% do } \\
\text { total } \\
\text { de estab. }\end{array}$ & $\begin{array}{c}\text { Área } \\
\text { (mil ha) }\end{array}$ & $\begin{array}{c}\text { \% do } \\
\text { total } \\
\text { da área }\end{array}$ & $\begin{array}{c}\text { VBP } \\
\text { (mil R\$) }\end{array}$ & $\begin{array}{c}\text { \% do } \\
\text { total } \\
\text { do VBP }\end{array}$ & $\begin{array}{c}\text { FT } \\
\text { (mil R\$) }\end{array}$ & $\begin{array}{c}\text { \% do } \\
\text { total do } \\
\text { FT }\end{array}$ \\
\hline A & 406291 & 8,4 & 24141455 & 6,8 & 9156373 & 19,2 & 433295 & 11,7 \\
B & 993751 & 20,4 & 33809622 & 9,6 & 5311377 & 11,1 & 228965 & 6,2 \\
C & 823547 & 16,9 & 18218318 & 5,2 & 1707136 & 3,6 & 68911 & 1,9 \\
D & 1915780 & 39,4 & 31599055 & 8,9 & 1942838 & 4,1 & 206656 & 5,6 \\
\hline TOTAL & 4139369 & 85,1 & 107768450 & 30,5 & 18117725 & 37,9 & 937828 & 25,3 \\
\hline
\end{tabular}

Fonte: INCRA/FAO (2000: 41).

De acordo com Anjos (2003: 343) "longe de representar uma forma social de produção destinada a desaparecer definitivamente no curso da história, a agricultura familiar parece consolidar-se como realidade estrutural e permanente, que forma parte dos sistemas agrários da quase totalidade dos países desenvolvidos". O reconhecimento dela, como parte importante da composição do rural e desempenhando funções agora um pouco mais consideradas, traz novos componentes para a discussão das estratégias e das prioridades de desenvolvimento rural.

A importância que a produção familiar desempenha na agricultura, faz com que ela seja um setor único no capitalismo contemporâneo. Segundo Abramovay (1992: 209) "não há atividade econômica em que o trabalho e a gestão estruturem-se tão fortemente em torno de vínculos de parentesco e onde a participação de mão-de-obra não contratada seja tão importante".

Finalmente, a agricultura familiar se estrutura "como uma nova categoria política, portadora de uma considerável fonte de legitimidade social, que simultaneamente representa os interesses dos pequenos produtores rurais, das famílias assentadas, dos arrendatários, dos agricultores integrados aos complexos agroindustriais e de outros atores sociais do campo brasileiro" (Anjos, 2003: 245). 
Para Veiga (2001) a sociedade brasileira tem que escolher entre dois projetos para o campo. Um deles tem como objetivo a maximização da competitividade do agribusiness, através da minimização dos custos de produção. Com isso, a busca por tecnologias mais avançadas leva à especialização crescente da produção agropecuária, o que torna desnecessária a mão-de-obra menos qualificada, reduzindo cada vez mais os postos de trabalho. Já o outro projeto tem por objetivo a diversificação das economias locais. Enquanto o primeiro projeto tem caráter setorial, o segundo busca a diversidade multi-setorial, valorizando a dinâmica gerada por famílias que vão se tornando pluriativas.

Conforme Veiga (2003: 136) "é inimaginável que a sociedade brasileira não venha a se dar conta do preço que está pagando por acreditar no mito da maior eficiência da agricultura patronal". E, ainda segundo o autor, "um dia acabará percebendo que a periclitante eficiência alocativa de um punhado de 'reis' do gado, da cana, do arroz ou da soja, nem de longe compensa sua absurda ineficiência distributiva".

O mais importante é o reconhecimento da existência e da importância destas duas opções bastante antagônicas. No entanto, não seria necessário priorizar entre um projeto ou outro, mas sim, atentar para a diversidade do meio rural brasileiro, onde há espaço para o desenvolvimento tanto da produção de commodities, como da diversificação da agricultura familiar.

Mais do que priorizar um setor ou outro dentro da agropecuária, é fundamental que se olhe para o rural como um território que desempenha não só as funções de produção de alimentos, matérias-primas e moradias, mas que sofre mudanças, implicando novas funções incorporadas e suscitando oportunidades diversificadas para a população ali residente.

\section{UM RURAL CADA VEZ MAIS COMPLEXO}

A complexidade de se estudar o meio rural brasileiro passa pela compreensão da diversidade e das particularidades que permeiam a constituição dos sistemas produtivos pelo seu vasto território. É consenso que o mundo rural foi, e vem sendo, palco de mudanças significativas, como aliás, é natural no processo de evolução das sociedades. No entanto, há divergências em relação à intensidade dessas transformações.

Olhar para o rural contemporâneo requer primeiramente que se atente para sua diversidade. Esta palavra não pode ser esquecida ao se analisar o rural, seja qual for a dimensão. A visão simplista do rural como agrícola vai ficando totalmente superada, pelo menos como campo de análise, já que novas funções vão sendo consolidadas e incorporadas nas estratégias de reprodução de muitas das famílias que habitam esse espaço.

As atividades não agrícolas, que compõem a pluriatividade de uma parcela significativa das famílias que residem no rural brasileiro, são muito importantes para a permanência de muitas delas no campo. 


\section{O crescimento da pluriatividade}

As atividades não agrícolas exercidas no seio de muitas famílias rurais passam a ser importante objeto de análise de muitos pesquisadores (Balsadi, 1997; Silva, 1997, 2001; Schneider, 1999; Mattei, 1999; entre outros), intrigados com a crescente conjugação de diferentes atividades e principalmente pela atração que o rural vai despertando nos citadinos, bem como a forma com que as famílias rurais vão respondendo a essas demandas.

Estas atividades estão presentes em praticamente todo o rural, embora com intensidade diferente, dependendo da região, compondo a pluriatividade das famílias rurais que, conforme Carneiro (1998: 148), se referem "às atividades complementares ou suplementares à produção agrícola exercidas por um ou vários membros de um grupo doméstico".

O crescimento das atividades não agrícolas no rural implicou que se incorporassem novos elementos não só nos métodos de análise, mas principalmente nas políticas direcionadas ao desenvolvimento deste espaço. Foi necessário, também, que se definissem os agricultores que realizavam outra atividade além da agrícola em suas propriedades ou fora delas. Duas noções ganharam destaque neste ínterim: a de pluriatividade e a de agricultura em tempo parcial.

Para Teixeira (1998) as noções de pluriatividade e agricultura em tempo parcial se distinguem, na medida em que a pluriatividade leva em consideração não apenas a força de trabalho individual do chefe da exploração (que também ocorre na agricultura em tempo parcial), mas de todos os membros da família. Ela tem em conta, também, a descontinuidade temporal do trabalho agrícola, incluindo outras formas de produção que não sejam necessariamente remuneradas em dinheiro.

De acordo com Del Grossi e Silva (1998), o conceito de pluriatividade permite que se juntem as atividades agrícolas com outras atividades que geram ganhos monetários e não-monetários, independentemente de elas serem internas ou externas à exploração agropecuária. Para os autores o termo pluriatividade engloba os conceitos de diversificação produtiva e de agricultura em tempo parcial.

A noção de pluriatividade é a melhor forma de definir o fenômeno da multiplicidade de formas de trabalho e renda das unidades agrícolas, sendo esse termo utilizado para descrever o processo de diversificação que ocorre dentro e fora da propriedade, bem como o surgimento de um conjunto de novas atividades que ganham espaço no rural (Schneider, 1999).

A pluriatividade é a mais adequada forma de designar a presença de atividades não agrícolas nas famílias rurais. Segundo Alentejano (2001: 154) “(..) permite dar conta melhor do caráter familiar da unidade agrícola, pois parte dos membros pode dedicar-se até integralmente ao trabalho agrícola, enquanto outros trabalham em outras atividades, o que não caracterizaria agricultura em tempo parcial - referida normalmente apenas ao chefe da exploração -, porém 
enquadra-se na noção de pluriatividade, se falarmos não apenas de indivíduos pluriativos, mas, fundamentalmente, de unidades familiares calcadas no trabalho pluriativo".

Ela resulta do esforço empreendido pelos pequenos produtores rurais para se inserirem em novos mercados locais, e pode ser considerada uma etapa da diferenciação social e econômica pela qual passam as famílias agrícolas, que não conseguem se reproduzir apenas no espaço agrícola do novo mundo rural (Silva et al.,, 2001).

A pluriatividade possibilita a permanência dos agricultores no campo, pois proporciona que estes continuem com as atividades agropecuárias mesmo não sendo estas rentáveis: "dado um contexto de esvaziamento do campo associado à desvalorização da profissão de agricultor e às dificuldades crescentes da agricultura em garantir o necessário à reprodução social dos produtores e de seus familiares, a pluriatividade surge como uma alternativa à emigração e à exclusão do processo produtivo, possibilitando a permanência no campo e assegurando a continuidade da atividade agrícola mesmo quando esta não é mais considerada rentável economicamente" (Carneiro, 1998: 203).

Para Alentejano (2001: 155) é fundamental que se perceba "que essas múltiplas estratégias representam o caminho, às vezes único, para assegurar a reprodução da unidade familiar agrícola, quer porque a renda dita complementar é essencial, quer porque a especialização na atividade agrícola não aparece como opção desejável para os descendentes".

De acordo com Carneiro (1998: 150) as pequenas aldeias rurais são campo fértil para a construção de um novo padrão de produção agrícola, abrindo-se espaço também para a pluriatividade, considerada como um novo tipo de exploração rural. Para a autora as "regiões desfavoráveis à intensificação da agricultura e à instalação das grandes explorações capitalistas, como as zonas de montanha, por exemplo, são tradicionalmente espaços abertos à prática de atividades complementares não-agrícolas".

Essa nova dinâmica produzida pelas atividades não agrícolas traz a possibilidade de que famílias continuem residindo no campo independente das atividades que exerçam. Segundo Veiga (2003: 78) a "pluriatividade da agricultura familiar, que sempre ignorou fronteiras entre o rural e o urbano, é o inverso da expulsão prematura de trabalho inerente à opção pela fazenda patronal".

A dinâmica da economia rural, segundo Veiga (2000: 193), já não é mais determinada pelas riquezas naturais, mas sim pela presença crescente de aposentados, moradores temporários e turistas. Devido a isso, "o desenvolvimento de inúmeras áreas rurais tenderá a depender muito mais da segmentação de mercados locais ou regionais impulsionada por residentes temporários, turistas, esportistas, aposentados, etc., do que de padronizados mercados nacionais ou externos que absorvem commodities e manufaturados".

No entanto, de acordo com Alentejano (2001: 169), a pluriatividade não deve ser considerada como única saída, pois, em algumas regiões as condições para o seu desenvolvimento não estão presentes, enquanto em outras, as ativi- 
dades agrícolas poderão produzir melhores resultados. Para o autor "não devemos cair no equívoco de criar mais uma dicotomia, mas, sim, criar condições para a multiplicação de estratégias de desenvolvimento no meio rural, de forma a garantir condições de vida mais digna para a população que habita hoje o meio rural, assim como para aqueles que poderão vir a buscá-lo como alternativa de sobrevivência".

O desenvolvimento de muitas áreas rurais brasileiras passa pela percepção da diversidade e das peculiaridades que cada uma possui. Identificar o potencial de cada local é fundamental na elaboração de políticas de desenvolvimento rural. Certamente, em muitos, as atividades agropecuárias precisarão ser mais incentivadas, mas em outros as atividades não agrícolas poderão compor as estratégias de desenvolvimento. Nesse contexto, o turismo e o lazer podem desempenhar um papel importante.

\section{A emergência de novos valores}

As transformações recentes do mundo rural brasileiro são marcadas por dois fatos importantes. Um deles é o reconhecimento, pela primeira vez na história, da agricultura familiar como um ator social importante, sendo o Programa de Apoio a Agricultura Familiar (PRONAF) uma expressão dessa valorização. $\mathrm{O}$ outro fato está relacionado à demanda pela terra e aos assentamentos de reforma agrária. Isso se traduz na revalorização do rural como lugar para se trabalhar e para se viver (Wanderley, 2000).

O meio rural seria então um espaço diferenciado, não sendo mais apenas um lugar de produção agropecuária, mas um meio capaz de proporcionar aos citadinos padrões de residência bastante específicos, além de ser espaço para formas de lazer ligadas ao contato com a natureza (Wanderley, 2002).

Um dos mais importantes fenômenos demográficos, sociais e culturais do início do milênio é a revalorização das regiões interiores. Para Abramovay (2003: 98) "uma visão territorial do desenvolvimento pode revelar potenciais que, até hoje, o meio rural não revelou à sociedade. Visto como a base física da produção agrícola, seu destino dificilmente escapa à tragédia do esvaziamento social, econômico, político e cultural. Quando, entretanto, o meio rural é encarado, não como a simples sustentação geográfica de um setor (a agricultura), mas como base de um conjunto diversificado de atividades e de mercados potenciais, seus horizontes podem ser ampliados".

De acordo com Veiga (2004: 63) tornou-se cada vez mais forte nos últimos 20 anos um fenômeno novo em todas as sociedades mais desenvolvidas, que diz respeito à atração que os espaços rurais exercem e que resulta do grande aumento da mobilidade com um crescente leque de deslocamentos. Segundo o autor, nos últimos tempos "as principais vantagens comparativas voltaram a ser riquezas naturais, mas de outro tipo. São os encantos do contexto rural - beleza paisagística, tranqüilidade, silêncio, água limpa, ar puro - todas ligadas à qualidade do meio ambiente natural". 
Para Giuliani (1990: 60) valores típicos do velho mundo rural que estavam em vias de extinção, se revigoram e começam a ganhar para si a adesão dos citadinos. Esse fenômeno é denominado pelo autor de neo-ruralismo e acontece "quando as pessoas decidem não mais morar na cidade e não mais trabalhar em profissões urbanas, resolvendo se mudar para o campo e trabalhar na agricultura ou na criação de animais". Ainda de acordo com ele (1990: 64) "o neo-ruralismo se caracteriza por dimensões afirmativas, como a valorização da natureza e da vida cotidiana, a busca de autodeterminação, do trabalho como prazer, da integralização do tempo e das relações sociais".

Analisando os processos e sentidos sociais do rural contemporâneo Ferreira (2002: 36) coloca que: "a nova paisagem e os processos produzidos pela integração de atividades não agrícolas nos estabelecimentos rurais e pela pluriatividade dos agricultores e seus familiares, o aumento de uma população rural não agrícola e de aposentados que moram no campo, trazem um fenômeno de diversificação no meio rural. No entanto, não se pode pensar o rural brasileiro nos termos em que é pensado nos países de capitalismo avançado: nossa realidade não dá suporte para uma representação do rural como predominantemente não agrícola".

Para a autora, os agricultores estão valorizando as oportunidades disponíveis nos seus espaços rurais e colocando em prática estratégias de diversificação de seus estabelecimentos, de pluriatividade, de associativismo e de agroindustrialização em pequena escala. Assim, "temos no Brasil uma ruralidade em reconstrução, sob um processo complexo, não unidirecional, e que se revitaliza na sua complementaridade intrínseca com o urbano e que ainda carece de análises, estudos locais e regionais acerca de suas singularidades" (Ferreira, 2002: 41).

Esse emergir de uma complexidade cada vez maior do espaço rural, tem uma série de implicações quando se busca compreender essa realidade, principalmente no que diz respeito às inter-relações das atividades agrícolas e não agrícolas.

\section{CONSIDERAÇÕES FINAIS}

Num primeiro momento, foram analisadas algumas das principais características do rural brasileiro ao longo do século XX, principalmente enfocando a forma de organização do espaço produtivo. Das grandes plantações cafeeiras da primeira metade do século, passando pelo processo de modernização da base técnica na agropecuária e chegando ao final do século, em que a categoria dos agricultores familiares e a sua pluriatividade passam a ter importância crescente nas discussões sobre as estratégias de desenvolvimento para o rural.

Historicamente a agricultura para exportação foi privilegiada pelas políticas públicas, tendo o processo de modernização da agropecuária contribuído grandemente para o êxodo rural. Esse processo foi marcado pela redução da mãode-obra empregada no campo e pela concentração, tanto da posse da terra como da renda produzida no rural. 
Só em tempos recentes a agricultura familiar passou a fazer parte do debate sobre o desenvolvimento rural e a ter políticas específicas para a sua promoção. Há um crescente reconhecimento por parte dos órgãos oficiais de que a agricultura familiar tem importância fundamental no seu desenvolvimento. No entanto, segundo Veiga (2003: 133) "as vantagens de uma estratégia de desenvolvimento rural que priorize a promoção da agricultura familiar ainda não foram percebidas pela sociedade brasileira".

Os estudos das atividades agropecuárias não são mais suficientes para que se possa compreender a dinâmica do espaço rural. Ocorreu uma evolução dos usos desse espaço, com o surgimento e emergência de novas aptidões que levam a um novo olhar sobre o rural e a uma redefinição das suas atribuições. Nesse sentido, a definição do que seja o espaço rural vem sendo discutida e alterada, ou seja, o conceito de espaço rural vem sendo redefinido.

Isso ocorre devido ao desenvolvimento de novas funções e novos tipos de ocupações no espaço rural, que passa a ser percebido como um espaço com diversas atribuições, não somente em relação à produção que nele se realiza, mas também pela atração que exerce cada vez mais nos citadinos. Nesse sentido, há um processo de valorização do campo, principalmente pelos urbanos, que passam a enxergá-lo não mais como lugar de atraso. Essa percepção em relação ao rural e ao natural se intensificou, na medida em que a sociedade se urbanizou e os problemas desse processo começaram a ser sentidos pela população. A partir daí passa a haver a associação do rural e da natureza, à saúde, à liberdade, à qualidade de vida, ao descanso, etc.

Entendemos que o desenvolvimento rural não se reduz ao desenvolvimento agrícola, e concordamos com o alerta de Abramovay (2003: 83) quando coloca que, "por mais relevante que seja o estudo das atividades não agrícolas no meio rural, a questão do desenvolvimento, porém, não se restringe às possibilidades de sua expansão".

É fundamental, no entanto, que as estratégias de desenvolvimento para o rural brasileiro levem em consideração a grande diversidade presente nesse espaço e valorizem as potencialidades que cada local oferece, para que se consiga ultrapassar a situação de abandono em que muitas áreas rurais brasileiras se encontram.

\section{BIBLIOGRAFIA}

Abramovay R (2003) O futuro das regiões rurais. Editora da UFRGS, Porto Alegre, RS.

Abramovay R (1992) Paradigmas do capitalismo agrário em questão. Hucitec/ANPOCS/Editora da Unicamp, São Paulo/Rio de Janeiro/Campinas.

Albuquerque M C C, Nicol R (1987) Economia agrícola: o setor primário e a evolução da economia brasileira. McGraw-Hill, São Paulo.

Alentejano P R R (2001) Pluriatividade: uma noção válida para a análise da realidade agrária brasileira? In Tedesco J C (org.) Agricultura familiar: realidades e perspectivas. UPF, Passo Fundo, RS: 147-173. 
Alentejano P R R (2000) O que há de novo no rural brasileiro? Terra Livre, 15: 87-112.

Anjos F S (2003) Agricultura familiar, pluriatividade e desenvolvimento rural no sul do Brasil. EGUFPEL, Pelotas, RS.

Balsadi O V (1997) Emprego agrícola no Brasil e no Estado de São Paulo nos anos 90. Ops, 7(2): $15-23$.

Carneiro M J (1998) O ideal rurbano: campo e cidade no imaginário de jovens rurais. In Santos R, et al (orgs.) Mundo rural e política: ensaios interdisciplinares. Campus, Rio de Janeiro: 95-118.

Del Grossi M E, Silva J G (1998) A pluriatividade na agropecuária brasileira em 1995. In Aguiar D, Pinho J B (eds.) O agronegócio brasileiro: desafios e perspectivas, SOBER, Brasília: 635-646.

Delgado G C (1983) Capital financeiro e agricultura no Brasil: 1965-1985. Ícone Editora, São Paulo.

Ferreira A D D (2002) Processos e sentidos sociais do rural na contemporaneidade: indagações sobre algumas especificidades brasileiras. Estudos Sociedade e Agricultura, 18: 28-46.

Fürstenau V (1987) A política de crédito rural na economia brasileira após 1960. Ensaios FEE: $139-154$.

Furtado C (1964) Formação econômica do Brasil. Fundo de Cultura, São Paulo (6. a edição).

Giuliani G M (1990) Neo-ruralismo: o novo estilo dos velhos modelos. RBCS, 14: 59-67.

Gremaud A P, et al. (1997) Formação econômica do Brasil. Atlas, São Paulo.

IBGE - Instituto Brasileiro de Geografia e Estatística (2006) Estatísticas do Século XX. Brasil.

INCRA/FAO (2000) Novo retrato da agricultura familiar: o Brasil redescoberto. Projeto de Cooperação Técnica INCRA/FAO, Brasília.

Mattei L F (1999) Pluriatividade e desenvolvimento rural no estado de Santa Catarina. Dissertação de Doutoramento em Ciências Econômicas. SP. Instituto de Economia da Universidade de Campinas, Campinas.

Moreira R J (1999) Agricultura familiar: processos sociais e competitividade. Mauad; UFRRJ/CPDA; REDCAPA, Rio de Janeiro.

Schneider S (1999) Agricultura familiar e industrialização: pluriatividade e descentralização industrial no Rio Grande do Sul. Editora da UFRGS, Porto Alegre, RS.

Silva J G (2001) Velhos e novos mitos do rural brasileiro. Estudos Avançados, 15(43): 37-50.

Silva J G (1998) A nova dinâmica da agricultura brasileira. IE/UNICAMP, Campinas, SP (2. ${ }^{\text {a }}$ edição).

Silva J G (1997) O novo rural brasileiro. In Shiki S et al (orgs.) Agricultura, meio ambiente e sustentabilidade no cerrado brasileiro. Uberlândia, MG: 75-100.

Silva J G (1988) A gestão das políticas agrícolas numa agricultura moderna. In Anais do XXVI Congresso Brasileiro de Economia e Sociologia Rural. SOBER, São Paulo: 244-273.

Silva J G, et al. (2001) Turismo em áreas rurais: suas possibilidades e limitações no Brasil. In Almeida J A et al. (orgs.) Turismo rural e desenvolvimento sustentável. Papirus, Campinas, SP: $15-62$ (2. ${ }^{\mathrm{a}}$ edição).

Singer P (1998) Economia política da urbanização. Contexto, São Paulo (14. a edição).

Teixeira V L (1998) Pluriatividade e agricultura familiar na Região Serrana do Estado do Rio de Janeiro. Dissertação de Mestrado em Desenvolvimento, Agricultura e Sociedade. Rio de Janeiro, Universidade Federal Rural do Rio de Janeiro. 
Veiga J E (2004) Destinos da ruralidade no processo de globalização. Estudos Avançados, 5: 51-67.

Veiga J E (2003) Cidades imaginárias: o Brasil é menos urbano do que se calcula. Autores Associados, Campinas, SP (2. edição).

Veiga J E (2001) O Brasil rural ainda não encontrou seu eixo de desenvolvimento. Estudos Avançados, 15(43): 101-119.

Veiga J E (2000) A face rural do desenvolvimento: natureza, território e agricultura. Editora da UFRGS, Porto Alegre, RS.

Veiga J E (1991) O desenvolvimento agrícola: uma visão histórica. Editora da USP/Hucitec, São Paulo.

Wanderley M N B (2000) A emergência de uma nova ruralidade nas sociedades modernas avançadas - o "rural" como espaço singular e ator coletivo. Estudos Sociedade e Agricultura, 15: $87-145$

Wanderley M N B (2002) Territorialidade e ruralidade no Nordeste: por um pacto social pelo desenvolvimento rural. In Sabourin E, Teixeira, O A (ed.) Planejamento e desenvolvimento dos territórios rurais: conflitos, controvérsias e experiências. Embrapa Informação Tecnológica, Brasília: 39-52. 